\title{
Positioning Theory and the Negotiation of Information Needs in a Clinical Midwifery Setting
}

\author{
Pamela J. McKenzie \\ Faculty of Information and Media Studies, The University of Western Ontario, London, Ontario, Canada, N6A \\ 5B7. E-mail: pmckenzi@uwo.ca
}

Studies of everyday life information seeking have begun to attend to incidental forms of information behavior, and this more inclusive understanding of information seeking within broader social practices invites a constructionist analytical paradigm. Positioning theory is a constructionist framework that has proven useful for studying the ways in which interactional practices contribute to information seeking. Positions can construct individuals or groups of people in ways that have real effects on their information seeking. This article identifies some specific types of discursive positioning and shows how participants in a clinical care setting position themselves and one another in ways that justify different forms of information seeking and giving. Examples are drawn from an ongoing study of information seeking in prenatal midwifery encounters. The data consist of audio recordings of nine prenatal midwifery visits and of 18 follow-up interviews, one with each participating midwife and pregnant woman. The midwifery model of care is based on a relationship in which the midwife provides the pregnant woman with information and support necessary for making informed decisions about her care. Midwife-client interactions are therefore an ideal context for studying information seeking and giving in a clinical encounter.

\section{Positioning Theory and Information Seeking in a Clinical Midwifery Setting}

As library and information science (LIS) researchers have begun to focus on everyday life information seeking (or ELIS, Savolainen, 1995), they have also begun to attend to forms of information behavior beyond active or purposeful information seeking on the part of the individual. These varieties of information behavior encompass a range of practices which include actively scanning a source to meet a known information need, serendipitously encountering an unexpected source relevant to a future need, or being given information without actively seeking (for a review, see

$\overline{\text { Accepted December 3, }} 2003$

(C) 2004 Wiley Periodicals, Inc. • Published online 20 February 2004 in Wiley InterScience (www.interscience.wiley.com). DOI: 10.1002/asi.20002
McKenzie, 2003a). Many of these practices take place within everyday talk and may be dismissed as "chatting" by those who study more formal or directed forms of information seeking. Taking a more inclusive understanding of ELIS within broader social practices allows for the study of information seeking as information practice situated within social practices (Drew \& Heritage, 1992).

Savolainen (1995) suggested that an emphasis on the cognitive processes of the individual fails to capture the richness of information as constructed through the interaction of the individual and the sociocultural context. Tuominen, Talja, and Savolainen (Tuominen \& Savolainen, 1996; Tuominen, Talja, \& Savolainen, 2002) advocated a constructionist paradigm, which puts emphasis on social practices, "the concrete and situated activities of interacting people, reproduced in routine social contexts across time and space" (Rosenbaum, 1993, p. 239), and a number of LIS researchers are working within this paradigm (for recent examples, see Jacobs, 2001; Given, 2002; Sundin, 2002; Talja, 2002). In a constructionist approach, "the primary emphasis is on discourse as the vehicle through which the self and the world are articulated, and on the way different discourses enable different versions of selves and reality to be built" (Tuominen, Talja, \& Savolainen, 2002, p. 273). A focus on interpersonal practices rather than on behavior shifts the analysis from cognitive to social and allows us to see information needs, not as fixed entities residing in the head of the information seeker and brought to the information-seeking encounter, but rather as collaboratively negotiated and constructed over the course of the encounter itself. The negotiation of information needs can then be seen to be a significant function of everyday chatting, and the question of interest shifts from "What are the user's information needs and how does she seek information to meet them?" to "How are information needs collaboratively constructed in everyday conversation?"

Positioning theory is a constructionist framework that has proven useful for studying the relationships between interactional practices and information seeking. The act of positioning, or "the assignment of fluid 'parts' or 'roles' to 
speakers in the discursive construction of personal stories that make a person's actions intelligible and relatively determinate as social acts" (Harré \& van Langenhove, 1999, p. 17), can construct individuals or groups of people in ways that have real effects on information seeking. In a clinical interaction, for example, the right to make a diagnosis or give a directive varies between the professional and the patient. The two participants therefore occupy different discursive positions, and it is necessary to attend to the ways that the speakers position themselves and one another in order to understand the social meaning of what they say. Given (2002) has shown how the positioning of individual mature university students within broader "traditional student" and "mature student" constructions has had important implications for those students' information seeking and academic success. McKenzie and Carey (2000; McKenzie, 2002b, 2003b) studied positioning in individuals' accounts of seeking health-related information seeking and found that positioning theory "offers insight into the mutually specifying correspondence between local discursive practices and styles of information behavior" (McKenzie \& Carey, 2000). Positioning theory provides a framework for analyzing the ways that everyday talk shapes the individual's experience of the information-seeking episode and contributes to the co-construction of information needs by the participants.

This article identifies some specific types of discursive positioning used by Canadian midwives and pregnant women and shows how an analysis of positioning can contribute to the study of the information practices occurring within everyday conversation. Examples are drawn from an ongoing study of communication and information seeking in clinical midwifery visits.

\section{Pregnancy and Midwifery Care as Context for Information-Seeking Research}

Pregnancy and parenting are extremely rich contexts in which to study information seeking practices. LIS researchers and practitioners have discussed information services for pregnant women (see, for example, Gross, 1997) and parents, both in general (Feinberg \& Feldman, 1996; Lobosco, Keitel, Cohen, \& Simkin, 1996; White, Bell, \& McCallum, 2000), and in their roles as nurturers of children's emergent literacy (Meyers, 2002). Although Melissa Gross has demonstrated that parents can be the imposers of children's library queries (Gross, 1999), there have been very few published studies of pregnancy (McKenzie, 2002a, 2002b, 2003b) and parenting (Nicholas \& Marden, 1998) as information-seeking contexts. Likewise, although Pettigrew (1997) and McKenzie (2002a) reported that several kinds of information behavior occurred when individuals spent time in medical clinics, there have as yet been few analyses of clinical health communication from a library and information science (LIS) perspective (see Baker \& Connor, 1994; Wilson, 1997).
Research in other disciplines can shed light on pregnancy as a context for the study of information seeking. Medical anthropologists Carole Browner and Nancy Press suggest that getting and giving information is the fundamental function of American prenatal care, and that many women consider being informed to be "foremost among the responsibilities conferred by pregnancy" (Browner \& Press, 1997, p. 117). The "midwifery model" of practice is in fact based on a relationship in which the midwife provides the pregnant woman with information and support necessary for making informed decisions about her care (Rooks, 1999). Appropriate information giving and active client decisionmaking have been associated both with women's satisfaction with midwifery care and with positive postpartum outcomes (Green, Coupland, \& Kitzinger, 1990; Kennedy, 2000). Information exchange is therefore an integral component of the midwifery model of care, making a midwifeclient interaction an ideal site for studying the ways that information seeking and information giving are negotiated in a health care setting.

The bulk of research into patient communication with medical care providers concerns doctors, although a small number of studies have considered midwives (Fisher, 1991; McKay \& Smith, 1993; Rúdólfsdóttir, 2000; Tinkler \& Quinney, 1998; Trandel-Korenchuk, 1987). Linell and Bredmar (1996) analyzed the framing of sensitive topics in conversation in prenatal midwifery visits, Olsson and Jansson (2001) conducted a longitudinal study which followed five Swedish women through the entire course of their midwifery care, and Levy (1999) studied the ways that British midwives negotiated among several competing interests and needs to provide appropriate information and decision-making support.

This article reports initial findings from an ongoing study of midwife-client communication in the Canadian province of Ontario. The larger study uses the concept of the "information ground," a physical environment where informationseeking and exchange occur (Pettigrew, 1997), to analyze the information needs, seeking, giving, and exchange taking place when Ontario midwives and their pregnant clients meet in a clinic or home setting for prenatal visits. The study provides an opportunity to examine several specific information-seeking issues related to the physical space of the midwifery clinic and with relevance to both the everyday life information seeking of midwifery clients and the workplace information seeking of midwives. The goals of the larger study are to analyze the ways that participants in prenatal care encounters (1) position themselves and others as information seekers and information sources, (2) use accounts of information-seeking, giving, and use to position themselves in relation to various personal or professional roles they might occupy, and (3) work together within the context of an "information ground."

In Canada, midwifery is a fully or partially licensed profession in six of the ten provinces and one of the three territories, and midwifery services are fully government funded in four provinces (Hawkins \& Knox, 2003, p. 41). 
The implementation of the Ontario Midwifery Act in 1994 (S.O., 1991, c. 31) established midwifery as a fully licensed profession in the province of Ontario. Although some Ontario midwives also have nursing training, midwifery and nursing are independent professions (Bourgeault \& Fynes, 1997). Ontario midwives provide primary care for low-risk women and their babies during pregnancy, birth and for 6 weeks postpartum. In many practices, a small group of midwives will share the care of each client. Midwifery services are fully funded by the Ontario Ministry of Health and Long-Term Care. With the exception of aboriginal midwives practicing in their own communities, midwifery practice is regulated by the College of Midwives of Ontario. Midwives qualify for registration either by completing a 4-year Bachelor of Health Sciences in Midwifery Degree or by demonstrating sufficient prior learning and experience. Registered midwives are licensed to attend low-risk births both in hospital and at home. (Ontario, Ministry of Health and Long-Term Care, 2003). As of June 13, 2003, the College of Midwives of Ontario lists a total of 235 registered midwives practicing in 42 Ontario practices (College of Midwives of Ontario, 2003a, 2003b).

\section{Methods}

The examples analyzed in this article come from prenatal visits between nine pregnant women and their midwives practicing in large Ontario cities $(300,000$ to $1,000,000$ people). Data collection and analysis conform to ethical guidelines on research on human subjects of The University of Western Ontario and the Social Science and Humanities Research Council of Canada. The midwives in each practice were approached and indicated a willingness in principle to participate in the study. Client recruitment flyers were then placed in the waiting areas of the midwifery practices. Interested clients contacted the researcher who then contacted the attending midwife to determine whether she was willing to participate.

Participating midwives ranged from a recent graduate with less than 1 year's experience as a licensed midwife to a senior midwife with 20 years of experience. The clients ranged from 22 to 38 weeks pregnant at the time of their midwifery visit. For four women this was the first successful pregnancy while the other five had other children. All participating pregnant women had completed some post-secondary education and worked in customer service, arts, education, social service, or health care fields or were engaged in full-time childcare. All were either married or living in common-law relationships with the fathers of their babies, and they ranged in age from 28 to 38. [In Ontario in $1996,78.3 \%$ of live births were to women between the ages of 25 and 39 (Statistics Canada, 1999).]

Two major forms of data were collected. First, I recorded a regular prenatal visit between each of the participating clients and her primary midwife. Prenatal midwifery visits generally occur once per month for the first 26 weeks of pregnancy, once every 2 weeks until week 36 , and then once a week until the birth. They may take place in the midwifery clinic or in the client's home. Like a medical appointment, the prenatal visit follows a common pattern: Visits generally begin with a discussion of matters of concern to the pregnant woman, proceed to a discussion of issues on which the pregnant woman will need to make decisions (such as place of birth and whether to participate in various forms of prenatal testing), and finish with a physical examination (Hawkins \& Knox, 2003, pp. 91-92).

All nine prenatal visits took place in midwifery clinics. Either my co-investigator or I met participants shortly before the prenatal visit to explain the study and obtain informed consent. After setting up the recorder in the examining room, the researcher left and waited in the waiting area or some other convenient location until the visit was completed. Videotaping and observation were considered for this project but were rejected as too obtrusive.

A midwife and a client were present at all nine prenatal appointments. In addition, senior-year midwifery students participated in some visits, and clients' partners and children were present at some. The substantive portion of the prenatal visit (measured using the transcriber counter from the time the researcher left the room and conversation began until the moment when the midwife and client began discussing the booking of the next appointment and/or conversation became very social) ranged from 27.1 minutes to 35.7 minutes, with a mean of 33.0 minutes.

Second, I conducted and audio-recorded follow-up interviews with each midwife and client participant between 1 and 12 days after the prenatal visit. The midwife and client were interviewed individually and each participant's comments were kept confidential from the other participants. Follow-up interviews took place at a location of the participant's choice: midwife interviews in the midwives' homes or offices and client interviews in the clients' homes. A significant portion of each follow-up interview consisted of playing back the recording of the office visit and inviting the participant to stop the tape whenever she had something to say (for other uses of this technique, see Pomerantz, Fehr, \& Ende, 1997; Levy, 1999; McKay and Smith, 1993). In addition to the discussion of the specific appointment, the midwife and client interview schedules contain questions related to the other goals of the study.

Audio-recordings of the prenatal visit and the follow-up interviews were transcribed, and the transcripts analyzed for examples of positioning. Because of the small number of cases reported here, care has been taken to protect anonymity and confidentiality so that no participant will be able to recognize herself or her midwife/client as such recognition could potentially have negative implications for their future relationship. This results in some limitations in this initial reporting of the data. First, the examples reported here are deliberately drawn from routine discussion topics (such as nutrition, prenatal testing, and who will attend the birth), which were addressed in many or all of the prenatal visits, rather than uniquely identifiable topics (such as birth options after a previous Caesarian section) which might only 
have been addressed by one midwife-client pair. Second, the examples generally demonstrate the positive aspects of the midwife-client interaction. Although positioning can be used by participants to place one another in conflicting roles and can have important negative impacts on the quality of the interaction, such negative examples will be reported only once the study has recruited a sufficient number of participants to ensure confidentiality. Examples are therefore not intended to be representative of the experiences of all pregnant women receiving midwifery care nor to constitute a full accounting of this study. Rather, the examples reported here were specifically selected for their ability to illustrate the varieties of positioning described by Harré and van Langenhove (1999) and the insights they provide into information needs and seeking. Finally, I have not used pseudonyms to "tag" each quotation by participant, so that it is impossible to link the quotations throughout the article to a particular participant. This last decision is consistent with the guidelines of journals with a mandate to publish small-scale qualitative studies in health care settings (for example, Qualitative Health Research, 2003).

\section{Findings}

As McKenzie and Carey (2000) found, several forms of positioning have implications for health information seeking. The remainder of this article will provide examples of some of the varieties of positioning evident in prenatal midwifery encounters and describe the ways that these forms of positioning relate to the collaborative construction of information needs and the seeking or giving of information in this clinical setting.

\section{Self-Positioning and the Negotiated Construction of Information Needs}

An act of positioning situates both the speaker and the person spoken to: "For instance, if Jones says to Smith: 'Please iron my shirts,' then both Smith and Jones are positioned by that utterance. Jones as somebody who has the moral right (or thinks he has the moral right) to command Smith, and Smith as somebody who can be commanded by Jones" (Harré \& van Langenhove, 1999, p. 20). Jones' request constitutes a first order or performative positioning, one which takes place "within an ongoing and lived storyline" (Harré \& van Langenhove, 1999, p. 21) and has the effect of locating both Smith and Jones within that storyline. Individuals may position themselves, or others may position them, and positioning may be deliberate or it may be forced, for example in response to a question from someone else.

In the course of the prenatal visit, pregnant women frequently positioned themselves. The ways that positioning was responded to and taken up in subsequent conversation by the woman and the midwife determined the kinds of information needs that were articulated or inferred and the kinds of information offered. In the first example, the midwife's acceptance of the client's positioning led to the giving of socially supportive information: that the woman's concerns are legitimate and shared by others. The pregnant woman begins by positioning herself as annoyed and frustrated:

Pregnant woman: [I'm] fed up [chuckles].

Midwife: You're fed up.

Pregnant woman: I am.

Midwife: Yeah ... with being pregnant?

Pregnant woman: With being pregnant, with things going wrong every time I go for an ultrasound.

In this example, the pregnant woman provides evidence of her problematic pregnancy ("things going wrong every time I go for an ultrasound") to legitimize her feelings. Rather than challenging this positioning (for example, by saying "It's not really that bad"), the midwife accepts the client's representation of herself. Later in the same appointment, she refers to the pregnant woman's self-positioning in a way that both supports the positioning and invites a particular form of information giving:

Midwife: My sense is that you're feeling just fairly disgusted with everything right now.

Pregnant woman: Pretty much.

Midwife: Yeah.

Pregnant woman: This pregnancy thing's overrated [very loud burst of laughter from midwife, pregnant woman chuckles].

Midwife: Now I can find you an entire troupe of women who would agree with that, let me tell you, yes. The glowing and radiant features ... for some women that might be true but, yeah, for most women it's a mixed blessing [pregnant woman chuckles] in terms of the actual pregnancy itself. It's usually uncomfortable.

Pregnant woman: Yup.

The midwife demonstrates her acceptance of the legitimacy of the pregnant woman's discomfort and frustration by giving the client information that supports and normalizes her self-positioning. The midwife's claim that an "entire troupe" of women would feel the same way reinforces the appropriateness of frustration as a legitimate experience for a pregnant woman. The midwife does not rule out an alternative positioning for some pregnant women: "for some women that might be true," but she justifies the client's positioning by informing her that her feelings are well within the range of normal experiences of her peers: "for most women it's a mixed blessing."

In the first example, the client's positioning is unambiguous and the midwife responds by accepting it wholeheartedly and offering information that is consistent with this acceptance. In the next case, the pregnant woman positions herself in a much more ambivalent fashion. The midwife's response begins a negotiation of positions that is a necessary prelude to the determination of information needs and the joint decision of the appropriateness or inappropriateness of disclosure. 
Pregnant Woman: [The ultrasound technician] said she could tell the gender [of the baby] and I said include it [in the report to the midwife] just in case I want to know, but I don't think I want to know!

Midwife: Okay.

Pregnant Woman: You don't have to block it out, just in case, but, I don't think I want to know! I like the surprise at the end! So, I don't want to know.

Midwife: Okay. Well, I can put something over it just so somebody doesn't inadvertently [chuckling] say something to you or ...

Pregnant Woman: If they do, they do. You know.

Midwife: Yeah, okay.

Pregnant Woman: It's, it's not such a big deal. I'm not going to go and seek the information that's all.

Midwife: Okay.

Pregnant Woman: So if you block it then, I mean, what if I change my mind, right?

Midwife: Oh, I just put a sticker on it and we'll just lift the sticker up!! [Laughter.]

Pregnant Woman: Okay!! [Laughing.] That's nice, that's helpful. . . . So, maybe I'll tell you next time to block it. We're pretty set on not knowing, but just don't block it yet, just in case.

Midwife: Okay.

Pregnant Woman: Okay.

Midwife: That's fine. It's there.

Pregnant Woman: I figure I do a lot of hard work for 9 months, or 10 months, or 40 weeks, or whatever it is, I want a nice surprise at the end.

Midwife: Yeah.

In this excerpt, the pregnant woman positions herself as ambivalent, and the midwife responds by offering a flexible approach to disclosing the sex of the baby. Initially, the client positions herself as not wanting to know ("I like the surprise at the end! So, I don't want to know.") The midwife responds by accepting this positioning, offering to protect the client from the unintended disclosure of this information by covering that portion of the ultrasound technician's report with a sticker so that another midwife will not inadvertently mention it. When the client tempers her position ("it's not such a big deal" if she finds out inadvertently but that "I'm not going to go and seek the information that's all") and implies that she would not be upset if she the information were disclosed accidentally, the midwife supports this modified positioning by explaining that the sticker could easily be removed if the pregnant woman so chose.

The midwife's strategy both supports the pregnant woman's desire for "a nice surprise at the end" and accepts her right to change her mind about whether she wants to be told the baby's sex, without constructing one option as more desirable or appropriate. In this case, the information need is jointly constructed as contingent: It is a potential rather than a given fact. This fluid negotiation of an information need differs sharply from the common LIS understanding of information needs as previously existing in the mind of the user, and it reflects the dynamic practices and processes that occur in actual information-seeking encounters.
These two examples illustrate cases in which the pregnant woman positions herself in a particular way and the midwife accepts both the pregnant women's positioning and her right to take the lead in constructing the information need. Both midwives respond by either offering or not offering information in accordance with the information needs negotiated through the jointly constructed positioning. In other cases, other people positioned the pregnant woman and she was required to accept or contest the positioning in the course of her information seeking.

\section{Other-Positioning and the Imposed or Negotiated Construction of Information Needs}

As McKenzie and Carey (2000) found, medical texts position health information seekers by assigning them a specific place in a certain moral order-the "patient" role, with its attendant privileges and constraints-and provide no opportunity for the direct negotiation of first-order positions. Health care professionals or others can also position information seekers, but such positioning is more flexible. This other-positioning may be accepted by the information seeker or may be contested and renegotiated. This section describes two examples of other-positioning of the pregnant woman. In the first example, the midwife very carefully negotiates a position for the client as she gives her an information leaflet about the symptoms of premature labor:

Midwife: So this is, we give this out around this time and it's, just talks about risk factors for pre-term labor?

Pregnant Woman: Okay.

Midwife: Most people who have preterm labor are carrying more than one baby.

Pregnant Woman: Oh!

Midwife: That's the biggest risk factor.

Pregnant Woman: Okay. That's not the case, so.

Midwife: Nope [laughs]. Other people who have preterm labor sometimes can be because they use illicit drugs, um, they smoke a lot or too much alcohol. Under, undernourished people.

Pregnant Woman: Oh, okay.

Midwife: Can go into preterm labor, and then there's a small percentage of people who had absolutely no risk factors?

Pregnant Woman: It just happens.

Midwife: It just happens so we like to warn everyone, of the signs ahead of time....

The midwife first identifies multiple pregnancy as a risk factor for pre-term labor. The client responds by discounting this possibility ("that's not the case"), and the midwife immediately concurs with the client's self-positioning ("nope"), so that the position of carrying more than one baby is no longer available in this interaction. Next, the midwife identifies three risk factors that are associated with behavior for which the pregnant woman may be held responsible: drinking, smoking, and drug use. As Linell and Bredmar's (1996) study of Swedish midwives found, such 
sensitive topics require complex negotiation. In this case, neither the midwife nor the client attempted to position the client with respect to these kinds of behavior, in strong contrast to their immediate and joint rejection of the "multiple pregnancy" possibility. Rather than suggest that the client may be engaging in inappropriate behavior for a pregnant woman, the midwife provided a third positioning possibility with which the client may choose to associate herself. By stating that some cases of premature labor occur with "absolutely no risk factors," the midwife is able to justify giving the client information about the symptoms of premature labor without positioning her as someone who may be using tobacco, alcohol, or other drugs. The client reinforces this construction ("it just happens"), attributing some cases of premature labor to chance rather than to any behavior of the pregnant woman. The midwife can justify her information giving by placing the client within the broader category of "pregnant women": "We like to warn everyone." In this potentially difficult interaction, the midwife and the client have jointly constructed a position for the client that allows the midwife to give information about premature labor without compromising the pregnant woman's position as a responsible mother.

Although positions may derive from roles in a moral order (midwife, pregnant woman), and may be predicated on appropriate forms of behavior for people within those roles, positions are not fixed to roles and, once articulated, may be rejected or negotiated. The act of contesting or negotiating an other-positioning in the course of the same conversation is considered second-order positioning (Harré \& van Langenhove, 1999, p. 20). The following example provides an interesting counterpoint to the previous one. Here, the pregnant woman is positioned as potentially engaging in inappropriate behavior, in this case by her partner. The midwife and the pregnant woman engage in secondorder positioning to renegotiate this initial positioning before the midwife provides information.

The midwife has been asking how things are going, and they have discussed due dates, fetal movement, and scheduling of the next visit. This exchange follows immediately after that general discussion:

Midwife: And you're feeling well and everything's going well?

Pregnant woman: Yeah.

Partner: She's addicted to [desserts].

Pregnant woman: [Small laugh while talking] I'm not addicted, but I'm addicted to the fat. Well, we talked about this last time.

Partner: Donuts and chocolate.

Pregnant woman: More like heavy cake sort of thing. Midwife: Ahh.

In response to a fairly routine question, the woman's partner positions her quite forcefully ("she's addicted") as someone who has not been eating properly. The woman challenges the positioning right away by modifying the addiction ('I'm not addicted, but I'm addicted to the fat") and reminding the other participants that this is not a new concern, and neither is it something about which she has been secretive ("Well, we talked about this last time"). As the discussion progresses, the midwife and pregnant woman negotiate the partner's positioning to come to a resolution about the extent of the pregnant woman's transgression. At one point in the exchange, the pregnant woman says "I've been bad this whole pregnancy." The midwife responds to this comment by asking questions as she and the client negotiate positioning of the client

Midwife: Do you think you might be filling up on the carbohydrates, be it cake or others, instead of getting primarily?

Pregnant woman: [Interrupting] Probably.

Midwife: Proteins, vegetables, and fruit.

Pregnant woman: Yeah.

Midwife: Ah hah.

Pregnant woman: And, like if I'm sitting at dinner, I will eat salad because I feel I need to.

Midwife: Good. Good, salad's good.

Pregnant woman: I should be eating salad. But, I don't eat so much salad that I don't have room for [laughs] dessert! You know, that kind of thing? [Laughs.]

The client first agrees with the midwife's assessment, that she is "filling up on carbohydrates," but offers a tempered position. Her statement "I will eat salad because I feel I need to" indicates to the midwife that she is aware both of what kind of behavior is expected of her, and that she is behaving appropriately sometimes, if not all the time. The midwife reinforces the appropriateness of this kind of behavior for a pregnant woman ("salad's good"), and the pregnant woman responds by restating her awareness of the kind of behavior that is expected: "I should be eating salad." Her final statement places the desserts in discursive conflict with the salad: She knows what is expected and does it, although she transgresses at times. This is a much more moderate representation of her eating than the initial positioning that used the word "addiction." Immediately following this exchange, the midwife begins to give the client nutritional information. The renegotiated positioning reflects the pregnant woman's awareness of and compliance with directives about what pregnant women should do, and demonstrates her occasional deviation from the ideal. Having negotiated a positioning that is acceptable to both the midwife and client, the midwife now gives information consistent with this positioning:

Midwife: I understand. But, you know, it's, I mean balance and healthy nutrition. [Client laughs.] To get most of your calories and your energy needs met through, um, very full and rich nutrient sources. The best being vegetables.

Pregnant woman: Yeah.

Midwife: And protein sources including meats and ...

Pregnant woman: Yeah.

Midwife: Variety is good. 
The midwife's first act here is to say "I understand," accepting the pregnant woman as an aware and well-intentioned, but fallible, mother-to-be. Note that her instruction does not include the admonition that eating desserts is a poor nutritional choice. Rather, she gives advice about balance and information about what constitutes a good source of nutrition. The midwife goes on to offer several alternatives: "I encourage you to take a look at maybe trying to, um, renegotiate with yourself," to exchange a snack for a more nutritious option. However, she rejects the partner's absolute positioning of the pregnant woman as having an eating problem. For the midwife, there is a range of practices to be negotiated. She positions herself as a partner to the pregnant woman, assisting in modifying her habits without denigrating her behavior:

Midwife: I'm just trying to help you strategize around, I hear you saying, "I really think I eat a little bit too much on the sweet end of things and not enough on, sort of the building blocks nutritionally." And, and, probably the baby will be fine, but you might suffer for that. And it would be a good idea if we could turn it around a little bit. A treat once in a while is, you know, ah, it's not a bad thing.

The discursive conflict between "good food" and "junk food" during pregnancy has been analyzed by Markens, Browner, and Press (1997), who suggest that an onslaught of pregnancy advice from health service providers and the popular media makes pregnant women increasingly responsible for producing "good" babies, partly through compliance with biomedical understandings of "good" pregnancy diets. This midwife is therefore engaged in quite a skillful bit of positioning, as she is caught discursively between the pregnant woman's positioning of herself and her partner's initial positioning of her, which reflect a tension between the goal of the woman's free choice in her health care and the evidence that points toward one course of action over another. The information need ultimately responded to by the midwife is therefore the result of a joint negotiation between the midwife and client in response to the partner's positioning.

An analysis of the ways that pregnant women are positioned by themselves and others and the ways that such positions are subsequently accepted, rejected, and renegotiated in clinical midwifery encounters, provides insight into the ways that positioning creates an interactional environment in which certain kinds of information needs, seeking or giving are appropriate, while other kinds are not. The follow-up interview affords a source of subsequent reflection on the clinical visit and contains additional forms of positioning.

\section{Third-Order Positioning and the Negotiation of Source Authority}

In addition to the second-order negotiation of a position in the conversation as it unfolds, a speaker may contest or negotiate an other-positioning in a conversation with someone else (third-order positioning, Harré \& van Langenhove, 1999 , p. 21). Both second and third order forms of positioning are considered to be "accountive" as they take place within "talk about talk." Conducting follow-up interviews in which participants listen to a recording of the clinical encounter and are invited to comment on it creates a site for "talk about talk," an opportunity for accountive third-order positioning. The final example illustrates the multiple layers of analysis made possible by considering both the initial interaction and the third-order positioning evident in a later discussion of it.

In this case, a senior-year midwifery student participated in the prenatal appointment as with the midwife and client, and would be present at (and in fact taking primary responsibility for) the birth of the client's baby. In the final year of the Ontario midwifery education program, students undertake a clerkship in which they are "expected to participate in all phases of childbirth care in all available settings and should be increasingly able to devise the plan of care and make clinical decisions with minimal supervision" (McMaster University Midwifery Education Programme, 2003).

During the appointment, the midwife told a story that positioned the midwifery student in a way that emphasized her competence. Positions consist of both a "personal order" (relating to individual idiosyncracies) and "moral order" (the institutional aspects of social life which assign roles to people in discursive encounters-teacher/pupil, midwife/ pregnant woman, etc.; Harré and van Langenhove, 1999, pp. 21-22). Moral positioning can emphasize the category entitlement (Potter, 1996), or the characteristics that are associated with being a member of a particular role or category. Category entitlement is not automatically conferred on all members of a group, however, and neither is membership in a category automatic. For example, participants in a conversation can undermine the entitlement of an entire category ("I don't trust homeopaths, only M.D.s,") or they can question the right of an individual to be a member of the category ("I don't trust that M.D. She's a quack."). In this example, the midwife constructed a particular category entitlement for the student which she embedded in a story about a recent birth she and the student had attended. This story came up in the context of a discussion of incisions (episiotomies) and tearing during childbirth and followed the client's expression of the hope that she would not need to have stitches after giving birth:

Midwife: [Tearing] is related to how controlled the birth can be?

Pregnant woman: Mhmm.

Midwife: Um, and, um, you know, and just letting things stretch um, you know, [Student], um, had a birth, we were at a birth last week, and it was the woman's largest baby-it was, it was 8 [lbs] 14 [oz] [4015 g]—and I think she'd had episiotomies with her first two births, and she didn't even look like she'd had a baby after this one was born.

Pregnant woman: Oh, really? 
Midwife: So, yeah, yeah, so, absolutely no tearing at all, so. Pregnant woman: Mhmm.

The midwife tells this story as an account of a controlled birth against all odds. She introduces both the birthing woman (with her suggested previous need for incisions and ensuing stitches) and the baby (the woman's largest, with the weight provided as evidence of its substantial size) in such a way that the birth outcome ("absolutely no tearing at all") is presented as a significant accomplishment. The implication is that this accomplishment is linked to the efforts of the midwife and the student ("we"), in addition to the birthing woman and the baby, who together were able to "let things stretch" and keep the birth "controlled." The pregnant woman did not comment on this story during the follow-up interview. As I played the tape back for the midwife, however, she commented at this point to provide an explanation for the story:

Midwife: That was an intentional tale by the way [laughs]. I have a reputation for telling a lot of stories to women? But I think that, particularly someone like her, to have her experience drawn back into, what I see as being normal because she is really, so worried. ... That particular story I also just wanted to plant the seed, I mean, cause people sometimes get a little bit fearful around students, delivering their babies. So, the fact that, you know, I just sort of, you know, "[The student] delivered the baby and the baby was a good size and the woman had," [laughs] you know, "didn't have [stitches]." [Takes breath.] So, it will, it just also gives her a little bit of confidence that, you know, um, when it comes time for the birth that she's not getting, you know, less than what she would get if she were getting it from, from $m e$ being the person who's down there actually delivering the baby.

In the follow-up comment, the midwife herself is absent from the recounting of the birth story: the midwife positions the student as responsible for the achievement of the controlled birth, and therefore as someone who legitimately deserves the category entitlement of "midwife" despite her student status. In fact, the story positions her as not merely a midwife, but a good midwife, someone with the skills needed to deliver a large baby in such a way that the mother does not experience tearing. In addition, the midwife's comments in the follow-up interview serve to position the pregnant woman to whom the story is addressed. The midwife calls on the client's insecurity to justify her personal positioning that "particularly someone like her" who is "so worried" has a need for information that will reassure her about the competence of her care providers. In particular, the midwife uses moral positioning to place this client among the "people" who "sometimes get a little bit fearful around students delivering their babies." This positioning justifies the midwife's giving of reassuring information in the form of "an intentional tale" designed to provide evidence of the student's skill in order to inspire the pregnant woman's confidence in the information the student will give.

This final example demonstrates that an analysis of thirdorder positioning can provide further insight into the construction of information needs and the subsequent provision of information deemed by participants to be appropriate. In this last case, it is the midwife who takes the lead in positioning both the pregnant woman and the midwifery student, and makes the decision about what information should be given to the pregnant woman. In comparison with the other examples, the pregnant woman's voice is absent.

\section{Conclusion}

The examples presented in this article have been chosen to demonstrate the variety of performative (first-order) and accountive (second- and third-order) positioning that can occur in the clinical midwifery encounter and in later conversations about it. It is evident from these examples that the pregnant woman, midwife, and other participants actively position themselves and one another over the course of the clinical encounter, and that this positioning, whether accepted or reconfigured by participants, has an impact on the construction of information needs and on the consequent determination of what is appropriate information to seek or give.

Positioning theory gives LIS researchers new insight into the social practices within which everyday life information seeking takes place. In particular, positioning offers a glimpse into the ways that information needs come to be constructed among participants in a setting, and how those constructions invite or discourage information seeking or giving. Positioning theory provides a framework that permits the analysis of everyday talk to determine how "information needs" and "requests for information" are negotiated and constructed dynamically by the participants in the encounter. This analysis demonstrates that interpersonal interactions are an important site for the study of information needs, which are in fact negotiated through the very act of "chatting." Positioning contributes to the determination of the kinds of topics suitable and unsuitable for discussion (for example, the possibility of the pregnant woman's drug use), the information needs identified and acknowledged by participants (for example, the need for reassurance about the skills of a student or the appropriateness of negative feelings), and, finally, the kinds of information offered (or not offered) by the midwife (for example, information about the nutritional value of donuts).

Because the midwifery model of practice assumes and even requires an active relationship of information seeking and giving between the midwife and the client, the clinical midwifery setting is an ideal one for further study of practitioner-client interaction from an LIS perspective. Although the specific patterns of positioning described here are not necessarily transferable to other midwife-client encounters or to other types of clinical interactions, this article serves to demonstrate that the adoption of a construc- 
tionist perspective in general and positioning theory in particular can contribute to a deeper understanding of the variety of information practices that make up everyday life information seeking.

\section{Acknowledgments}

This research is funded by an internal research grant from the Faculty of Information and Media Studies of The University of Western Ontario and a standard research grant from the Social Sciences and Humanities Research Council of Canada. The author wishes to acknowledge the support of Jacquelyn Burkell, co-investigator on the internal research grant, and of the MLIS students who assisted in transcribing the data, and wishes to thank the three anonymous reviewers for their helpful comments on this article.

\section{References}

Baker, L.M., \& Connor, J.J. (1994). Physician-patient communication from the perspective of library and information science. Bulletin of the Medical Library Association, 82, 36-42.

Bourgeault, I.L., \& Fynes, M. (1997). Integrating lay and nurse-midwifery into the U.S. and Canadian health care systems. Social Science and Medicine, 44, 1051-1063.

Browner, C.H., \& Press, N. (1997). The production of authoritative knowledge in American prenatal care. In R.E. Davis-Floyd \& C.F. Sargent (Eds.), Childbirth and authoritative knowledge: Cross-cultural perspectives (pp. 113-131). Berkeley, CA: University of California Press.

College of Midwives of Ontario. (2003a). Finding a midwife by name. Retrieved July 27, 2003, from http://www.zfc-consulting.com/ webprojects/midwives/mss/home/findingName.asp

College of Midwives of Ontario. (2003b). Finding a midwife by region. Retrieved July 25, 2003, from http://www.zfc-consulting.com/ webprojects/midwives/mss/home/findingRegion.asp

Drew, P., \& Heritage, J. (1992). Talk at work: Interaction in institutional settings. Cambridge: Cambridge University Press.

Feinberg, S., \& Feldman, S. (1996). Serving families and children through partnerships: A how-to-do-it manual. New York: Neal-Schuman.

Fisher, S. (1991). A discourse of the social: Medical talk/power talk/ oppositional talk? Discourse \& Society, 2, 157-182.

Given, L.M. (2002). Discursive constructions in the university context: Social positioning theory and mature undergraduates' information behaviours. New Review of Information Behavior Research, 3, 127-142.

Green, J.M., Coupland, V.A., \& Kitzinger, J.V. (1990). Expectations, experiences, and psychological outcomes of childbirth: A prospective study of 825 women. Birth, 17, 15-24.

Gross, M. (1997). Library service to pregnant teens: How can we help? School Library Journal, 43(June), 36-37.

Gross, M. (1999). Imposed queries in the school library media center: A descriptive study. Library \& Information Science Research, 21, 501-521.

Harré, R., \& van Langenhove, L. (1999). Positioning theory. Oxford, UK: Blackwell.

Hawkins, M., \& Knox, S. (2003). The midwifery option: A Canadian guide to the birth experience. Toronto, Canada: HarperCollins.

Jacobs, N. (2001). Information technology and interests in scholarly communication: A discourse analysis. Journal of the American Society for Information Science and Technology, 52, 1122-1133.

Kennedy, H.P. (2000). A model of exemplary midwifery practice: Results of a Delphi study. Journal of Midwifery \& Women's Health, 45, 4-19.

Levy, V. (1999). Protective steering: A grounded theory study of the processes by which midwives facilitate informed choices during pregnancy. Journal of Advanced Nursing, 29, 104-112.
Linell, P., \& Bredmar, M. (1996). Reconstructing topical sensitivity: Aspects of face-work in talks between midwives and expectant mothers. Research on Language and Social Interaction, 29, 347-379.

Lobosco, A.F., Keitel, S., Cohen, B.P., \& Simkin, L. (1996). Serving families in the community: Library-based parent resource centers. Public Libraries, 35, 298-305.

Markens, S., Browner, C.H., \& Press, N. (1997). Feeding the fetus: On interrogating the notion of maternal-fetal conflict. Feminist Studies, 23, $351-372$.

McKay, S., \& Smith, S.Y. (1993). 'What are they talking about? Is something wrong?' Information sharing during the second stage of labor. Birth, 20, 142-147.

McKenzie, P.J. (2002a). Communication barriers and information-seeking counter-strategies in accounts of practitioner-patient encounters. Library \& Information Science Research, 24, 31-47.

McKenzie, P.J. (2002b). Connecting with information sources: Information seeking as discursive action. New Review of Information Behavior Research, 3, 161-174.

McKenzie, P.J. (2003a). A model of information practices in accounts of everyday-life information seeking. Journal of Documentation, 59, 19-40.

McKenzie, P.J. (2003b). Justifying cognitive authority decisions: Discursive strategies of information seekers. Library Quarterly, 73, 261-288.

McKenzie, P.J., \& Carey, R.F. (2000). "What's wrong with that woman?"Positioning theory and information-seeking behavior. In A. Kublik (Ed.), CAIS2000 Dimensions of a Global Information Science, Proceedings of the 28th Annual Conference of the Canadian Association for Information Science, School of Library \& Information Studies, University of Alberta, Edmonton, Alberta, May 28-30, 2000. Retrieved February 4, 2004, from http://www.slis.ualberta.ca/cais2000/mckenzie.htm

McMaster University Midwifery Education Programme. (2003). Midwifery courses. Retrieved July 27, 2003, from http://www.fhs.mcmaster. $\mathrm{ca} /$ midwifery/students/courseinfo.html

Meyers, E. (2002). Research maps new routes for reading success in PLA Early Childhood Initiative. Journal of Youth Services in Libraries, 15, 3-8.

Nicholas, D., \& Marden, M. (1998). Parents and their information needs; a case study: Parents of children under the age of five. Journal of Librarianship and Information Science, 30, 35-47.

Olsson, P., \& Jansson, L. (2001). Patterns in midwives' and expectant/new parents' ways of relating to one another in ante- and postnatal consultations. Scandinavian Journal of Caring Sciences, 15, 113-122.

Ontario, Ministry of Health and Long-Term Care. (2003). Health facts; women; midwifery in Ontario. Retrieved July 29, 2003, from http:// www.gov.on.ca/health/english/pub/women/midwife.html

Pettigrew, K.E. (1997). The role of community health nurses in providing information and referral to the elderly: A study based on social network theory. Unpublished doctoral dissertation, University of Western Ontario.

Pomerantz, A., Fehr, B.J., \& Ende, J. (1997). When supervising physicians see patients: Strategies used in difficult situations. Human Communication Research, 23, 589-615.

Potter, J. (1996). Representing reality: Discourse, rhetoric and social construction. Thousand Oaks, CA: Sage.

Qualitative Health Research. (2003). Qualitative Health Research author guidelines; writing hints. Retrieved July 27, 2003, from http://www. ualberta.ca/ qhr/guidelines.htm

Rooks, J.P. (1999). The midwifery model of care. Journal of NurseMidwifery, 44, 370-374.

Rosenbaum, H. (1993). Information use environments and structuration: Towards an integration of Taylor and Giddens. In S. Bonzi (Ed.), Proceedings of the 56th Annual Meeting of the American Society for Information Science (Vol. 30, pp. 235-245). Medford, NJ: Learned Information.

Rúdólfsdóttir, A.G. (2000). "I am not a patient, and I am not a child": The institutionalization and experience of pregnancy. Feminism \& Psychology, 10, 337-350. 
Savolainen, R. (1995). Everyday life information seeking: Approaching information seeking in the context of "way of life." Library \& Information Science Research, 17, 259-294.

Statistics Canada, Health Statistics Division. (1999). Births and deaths, 1997: Shelf tables. Ottawa, ON: Statistics Canada.

Sundin, O. (2002). Nurses' information seeking \& use as participation in occupational communities. New Review of Information Behavior Research, 3, 187-202.

Talja, S. (2002). Information sharing in academic communities: Types and levels of collaboration in information seeking and use. Information Seeking in Context: The Fourth International Conference on Information Needs, Seeking and Use in Different Contexts, Lisbon, Portugal. New Review of Information Behaviour Research, 3, 193-160.

Tinkler, A., \& Quinney, D. (1998). Team midwifery: The influence of the midwife-woman relationship on women's experiences and perceptions of maternity care. Journal of Advanced Nursing, 28, 30-35.

Trandel-Korenchuk, D.M. (1987). Disclosure practices of certified nursemidwives relative to methods of childbirth pain management. Journal of Nurse-Midwifery, 32, 131-139.
Tuominen, K., \& Savolainen, R. (1996). A social constructionist approach to the study of information use as a discursive action. In P. Vakkari, R. Savolainen, \& B. Dervin (Eds.), Information Seeking in Context: Proceedings of an International Conference in Information Needs, Seeking and Use in Different Contexts, August 14-16, Tampere, Finland (pp. 81-96). London: Taylor Graham.

Tuominen, K., Talja, S., \& Savolainen, R. (2002). Discourse, cognition, and reality: Toward a social constructionist metatheory for library and information science. In H. Bruce, R. Fidel, P. Ingwersen, \& P. Vakkari (Eds.), Emerging Frameworks and Methods: CoLIS 4. Proceedings of the Fourth International Conference on Conceptions of Library and Information Science, Seattle, WA, July 21-25, 2002 (pp. 271-283). Greenwood Village, CO: Libraries Unlimited.

White, M., Bell, M., \& McCallum, C. (2000). Great things come in small packages: A parent resource library. Journal of Youth Services in Libraries, $14,8-11$.

Wilson, T.D. (1997). Information behavior: An interdisciplinary perspective. Information Processing and Management, 33, 551-572. 